\title{
Evaluation of Immune Response to $r \sigma B$ Protein of Avian reovirus (ARV) in Chicken
}

\author{
S. Majumder ${ }^{1}$, T.K.S. Chauhan ${ }^{2}$, K. Dhama ${ }^{3}$, S. Nandi ${ }^{1}$, \\ P.P. Goswami ${ }^{2}$ and Deepak Kumar ${ }^{2 *}$
}

\author{
${ }^{1}$ Centre for Animal Disease Research and Diagnosis, Indian Veterinary Research Institute, \\ Izatnagar, 243122 (U.P.), India \\ ${ }^{2}$ Division of Veterinary Biotechnology, Indian Veterinary Research Institute, \\ Izatnagar, 243122 (U.P.), India \\ ${ }^{3}$ Avian Disease Section, Indian Veterinary Research Institute, Izatnagar, 243122 (U.P.), India \\ *Corresponding author
}

\section{A B S T R A C T}

Avian reovirus (ARV) is a non-enveloped double stranded RNA virus of poultry and is associated with significant economic losses to the poultry industry throughout the world. The virus is responsible for different clinical manifestations in poultry out of which most important is viral arthritis/tenosynovitis. Protein $\sigma \mathrm{B}$, an outer capsid protein of ARV

Keywords

Avian reovirus, Sigma B protein.

Article Info

Accepted:

15 March 2017

Available Online:

10 April 2017 contains group specific neutralizing epitopes and induces strong immune response in natural infection in chicken. We have evaluated the immunogenicity of full length roB fusion protein in chicken. Six, 4 week old, SPF chickens (Gr. A) were inoculated with 50 $\mu \mathrm{g}$ of $\mathrm{r} \sigma \mathrm{B}$ protein emulsified with Freund's incomplete adjuvant (FIA). Control birds (Gr.B and C) received FIA alone and PBS respectively. Blood samples were collected at 0 d.p.i, 7 d.p.i and 21 d.p.i to evaluate the level of cytokine expression towards roB. Serum neutralization test (SNT) was performed to analyze antibody response. There was significant up regulation of IFN- $\gamma$ and TNF- $\alpha 7$ d.p.i in group A birds. There was significant elevation in $(P<0.05)$ neutralizing antibody titre up to 6.3 in group A birds on 21 d.p.i, whereas there was no detectable neutralizing antibody response in control birds. There was significant increase in CD4+ Th cell population and reached up to $27.06 \%$ on 7 d.p.i. The rob fusion protein of ARV was able to generate good immune response in birds after primary immunization. This result suggests that roB fusion protein is a good candidate for preparation of subunit vaccine against ARV infection.

\section{Introduction}

Avian reovirus (ARV) belongs to the genus Orthoreovirus in the family Reoviridae and was first isolated from birds in 1954 (Fahey and Crawley, 1954). Virus particles are $70 \mathrm{~nm}$ to $80 \mathrm{~nm}$ in size, non-enveloped and have icosahedral symmetry with a double-shelled arrangement of surface protein. The genome of the virus is dsRNA with 10 segments.
Depending on their electrophoretic mobility the genome segments are divided into three size classes large (L1, L2, L3), medium (M1, M2, M3), and small (S1, S2, S3, S4) (Spandidos and Graham, 1976). Similarly, proteins encoded by the genome also fall into 3 size classes, as follows: $\lambda$ (large), $\mu$ (medium) and $\sigma$ (small). The ARV genome 
encodes for 8 structural and 4 nonstructural proteins. The 8 structural proteins are: $3 \lambda$ proteins $(\lambda \mathrm{A}, \lambda \mathrm{B}$ and $\lambda \mathrm{C})$ encoded by $\mathrm{L}$ segments, $2 \mu$ proteins ( $\mu \mathrm{A}$ and $\mu \mathrm{B}$ ) encoded by $\mathrm{M}$ segments, and $3 \sigma$ proteins $(\sigma \mathrm{A}, \sigma \mathrm{B}$ and $\sigma \mathrm{C}$ ) encoded by $\mathrm{S}$ segments (Varela et al., 1996). Four nonstructural proteins $\mu \mathrm{NS}, \sigma \mathrm{NS}$, are encoded by M3 and S4 segments respectively, while $\mathrm{S} 1$ segment encodes for 2 additional nonstructural proteins $\mathrm{p} 10$ and $\mathrm{p} 17$ (Bodelón et al., 2001).

The $\sigma \mathrm{B}$ protein encoded by the $\mathrm{S} 3$ gene segment is a major outer capsid protein of $\mathrm{ARV}$ is analogous to $\sigma \mathrm{C}$ protein of the mammalian reoviruses (Arnauld et al., 1999; Zhang et al., 2007). It is mainly involved in cell fusion (Ni and Ramig, 1993) and contains group specific neutralizing epitopes. The $\sigma \mathrm{B}$ protein is 367 amino acid long, with molecular mass of about $41.47 \mathrm{kDa}$ (Wickramasinghe et al., 1993).

Currently vaccination for ARV is mainly comprise of live attenuated vaccine in young chicks followed by inactivated vaccine for breeders intended to protect the young chicks by maternal antibodies. But both these vaccination strategies got disadvantages of their own including stability, maintenance of cold chain, duration of immunity etc. So there is an urgent need to develop a new vaccine to overcome these issues. Subunit vaccine has several advantages over the conventional one in terms of elimination of cold chain, enhanced efficiency of vaccination and ability to combine antigens with other vaccines (Nkando et al., 2016). In this study we have evaluated the immune response to $r \mathrm{~B}$ fusion protein of ARV in birds for further use of the protein as possible vaccine candidate.

Different immunological parameter including cytokine expression studies and evaluation of antibody response to $r \sigma B$ at different time interval was undertaken. Expression levels of different cytokines in response to $r \mathrm{~B}$ protein were evaluated by real time PCR. To confirm the results of real time PCR competitive ELISA was performed for IFN- $\gamma$ and TNF- $\alpha$, being the two most important cytokine produced by CD4+ cells. CD4+ and CD8+ cell response was analyzed by flow cytometry. Antibody responses to $r \sigma B$ in different group of birds were evaluated by mSNT.

\section{Materials and Methods}

\section{Protein}

The pARV- $\sigma$ B clone in One Shot ${ }^{\circledR}$ Mach1TM T1R (Invitrogen, USA) E. coli cells (Kumar et al., 2016) maintained in Division of Veterinary Biotechnology, ICAR-IVRI, Izatnagar, U.P. was revived and induced with $1 \mathrm{mM}$ IPTG at different time interval. The expressed $\mathrm{r} \sigma \mathrm{B}$ protein was purified using $\mathrm{Ni}$ NTA super flow cartridge, (Qiagen, USA) as per manufacturer's protocol. The protein was dialysed against PBS for $12 \mathrm{~h}$ followed by $4 \mathrm{~h}$ after addition of fresh PBS. The protein was quantified using Nano Drop Spectrophotometer (ND-1000; Thermo Fisher Scientific, USA).

\section{Birds}

Fertile SPF chicken eggs were procured from Venkateswara hatcheries Ltd., Pune, Maharastra. The chickens were not immunized for any disease and were fed according to their age. Vitamin and mineral supplement was given to the birds. Birds were reared as per institutional guideline.

\section{Immunization}

4 week old chickens were randomly divided into 3 groups of 6 birds each. chickens in Group A were immunized with $50 \mu \mathrm{g}$ of $\mathrm{r} \sigma \mathrm{B}$ in $350 \mu \mathrm{L}$ of PBS emulsified with equal 
volume of Freund's incomplete adjuvant (FIA), Group B birds received $350 \mu \mathrm{L}$ of sterile PBS emulsified with equal volume of FIA, Group C birds received only $700 \mu \mathrm{L}$ of sterile $\mathrm{PBS}$ via $\mathrm{I} / \mathrm{M}$ route in the breast muscle at multiple sites. Group B and C birds served as control.

\section{Collection of sample}

All the birds were bled on 0 d.p.i, 7 d.p.i and 21 d.p.i via jugular vein or wing vein. The blood with anticoagulant was collected for cytokine assay and FACS, another fraction was used for separation of serum to analyze antibody response.

\section{Antibody response to $\mathrm{r} \sigma \mathrm{B}$ protein}

Blood was collected from immunized and control groups were monitored for antibody response by micro-serum neutralization test (m-SNT). The m-SNT was performed as described previously (Giambrone, 1980) with slight modification. Briefly, the serum samples were incubated at $56^{\circ} \mathrm{C}$ for $30 \mathrm{~min}$, followed by serial two-fold diluted in increasing order from 1:2 to 1:1024 in sterile PBS. Then $50 \mu \mathrm{L}$ of each dilution of serum was transferred to a flat bottomed tissue culture microtiter plate.

Next, $50 \mu \mathrm{L}$ of cell culture adapted ARV containing $100 \mathrm{TCID}_{50}$ of virus was added followed by incubation at $37{ }^{\circ} \mathrm{C}$ at $5 \% \mathrm{CO}_{2}$ tension for $2 \mathrm{~h}$. Then $100 \mu \mathrm{L}$ of BHK-21 cell suspension containing approximately $2 \times 10^{5}$ cells/ $\mathrm{mL}$ was added to each well and incubated for $72 \mathrm{~h}$. The plates were examined under inverted microscope for appearance of cytopathic effect (CPE). The neutralization titer was determined as the dilution of serum giving 50\% neutralization end point. The SNT antibody titers were expressed as $\log _{2}$ reciprocal of highest dilution of the serum showing neutralization.

\section{Analysis of mRNA expression level of IFN- $\gamma$ and TNF- $\alpha$}

After inoculation $1 \mathrm{~mL}$ of heparinized blood was collected aseptically from test and control groups at different time intervals. PBMC was separated at each interval using Histopaq$1.077 \mathrm{~g} / \mathrm{ml}$ (Sigma, USA) following standard protocol. RNA was extracted from PBMC using TRI Reagent ${ }^{\circledR}$ (Sigma-Aldrich, USA) and the purity and concentration of the RNA was analyzed in a NanoDrop Spectrophotometer (ND-1000; Thermo Fisher Scientific, USA). Complementary DNA was synthesized from $1 \mu \mathrm{g}$ of RNA using Revert Aid First strand cDNA synthesis kit (Thermo Scientific, USA) according to maufacturer's protocol.

Cytokine specific primers for IFN- $\gamma$, TNF- $\alpha$ and housekeeping gene GAPDH (Nang et al., 2011) were used for analysis of expression level at different time interval and groups. Real time PCR was performed in Strategene Mx3005P Real Time Thermal Cycler (Agilent Technologies, USA) and results were analyzed using MxPro QPCR software. Real time PCR reaction mixture contained $5 \mu \mathrm{L}$ of EvaGreen qPCR Mastermix (G Biosciences ${ }^{\circledR}$, USA), $0.5 \mu \mathrm{L}$ each of forward and reverse primers and $1 \mu \mathrm{L}$ of cDNA as template, NFW was added to make the volume up to $10 \mu \mathrm{L}$.

The thermal profile used was 40 cycles of denaturation at $95{ }^{\circ} \mathrm{C}$ for $5 \mathrm{sec}$, annealing at $60{ }^{\circ} \mathrm{C}$ for $15 \mathrm{sec}$ and extension at $72{ }^{\circ} \mathrm{C}$ for 25 sec; after an initial denaturation at $95{ }^{\circ} \mathrm{C}$ for 5 min. For each gene of interest real time PCR was performed in duplicate.

No template control (NTC) where no cDNA was added to the reaction mixture was kept to rule out any reagent contamination. Housekeeping gene GAPDH was kept to normalize the expression level of these cytokines and TLRs. 
Competitive ELISA for estimation of cytokine concentration

ELISA for cytokines IFN- $\gamma$ and TNF- $\alpha$ was performed using competitive ELISA kit (Blue Gene Biotech Co., Ltd., Shanghai, China) as per manufacturer's instructions.

Analysis of CD4+ and CD8+ response by flow cytometry

Flowcytometric analysis of PBMCs was done for enumeration of CD4+ and CD8+ cells at different time interval. $100 \mu \mathrm{L}$ of PBMC containing approximately $10^{6}$ Nos. of cells were stained with $10 \mu \mathrm{L}(0.1 \mathrm{mg} / \mathrm{mL})$ of mouse anti-chicken CD4: FITC (AbD Serotek, USA) and mouse anti-chicken CD8: RPE monoclonal antibodies (AbD Serotek, USA) separately.

The cells were incubated at room temperature in dark. Then the cells were washed with 2 $\mathrm{mL}$ PBS and centrifuged. The pellet was resuspended in $200 \mu \mathrm{L}$ of PBS. The stained cells were acquired in a FACS Calibur ${ }^{\mathrm{TM}}$ flow cytometer (BD Biosciences, USA). A total of 10,000 events in the lymphocyte gate (based on forward and side scatter) were recorded from each sample and percentage variations in lymphocyte subpopulation were analyzed by FITC and RPE fluorescence at FL-1 and FL-2 channel using Cell Quest ${ }^{\mathrm{TM}}$ Pro Software (BD Biosciences, USA).

\section{Statistical analysis}

The result of m-SNT and kinetics of CD4+ and CD8+ cells of all three groups were analysed by Kruskal-Wallis test by IBM $^{\circledR}$ SPSS ${ }^{\circledR}$ 20.0. The P-value less than 0.05 was considered statistically significant. Result of TLR and cytokine expression studies were analyzed using the REST 2009 software, originally developed by Pfaffl, 2001 (Fig. 1).

\section{Results and Discussion}

\section{Antibody response to $\mathrm{r} \sigma \mathrm{B}$ protein}

At 0 d.p.i there was no detectable neutralizing antibody titer in either test or control groups as measured by mSNT. The GMT of serum neutralizing antibody in Gr. A birds raised significantly $(P<0.05)$ from 3.5 on 7 d.p.i reaching 6.3 and on 21 d.p.i. There was no detectable neutralizing antibody response to ARV in control groups.

\section{Cell mediated immune response}

\section{Cytokine}

There was significant increase in IFN- $\gamma$ and TNF- $\alpha$ expression level in Gr. A chicken on 7 d.p.i, but in case of control birds there was no change in expression level of these cytokines.

These results was supported by both Real Time PCR and cytokine specific competitive ELISA (Fig. 2).

\section{Analysis of $\mathrm{CD}^{+}$and $\mathrm{CD8}^{+}$cell percentage in PBMC}

In Gr. A the mean \pm SD percentage of CD4+ cells in PBMC raised significantly $(P<0.05)$ from $11.83 \pm 1.56 \%$ in 0 d.p.i to $28.96 \pm 0.89$ $\%$ on 7 d.p.i followed by $17.39 \pm 0.44 \%$ on 21 d.p.i. Whereas in Gr. B and C there was no significant change in $\mathrm{CD} 4+$ cell percentage and ranged between $8.68 \pm 1.23 \%-14.82 \pm$ $0.01 \%$ and $10.2 \pm 1.52 \%-12.67 \pm 0.31 \%$ respectively (Fig. 3).

The CD8+ cells did not show any significant change in proportion throughout the study and ranged between $3.30 \pm 0.87 \% \quad-5.855 \pm$ $0.67 \%$. 
Fig.1 Graphs represent the level of expression of mRNA of four cytokine transcripts in different groups at different time interval. The expression level was calculated by Pfaffl method using REST 2009 software after test samples were standardized with endogenous housekeeping (GAPDH) gene and caliberator (uninfected controls). The data was analysed with Scheirer-RayHare technique. (*) indicates $P<0.05$

\section{IFN-Y}

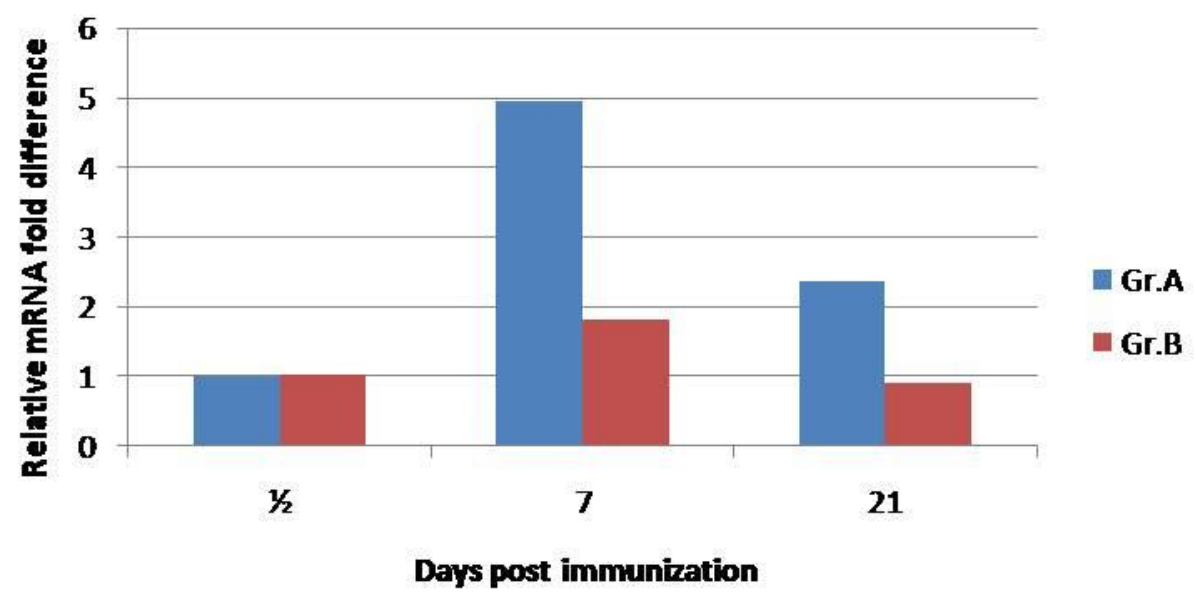

\section{TNF- $\alpha$}

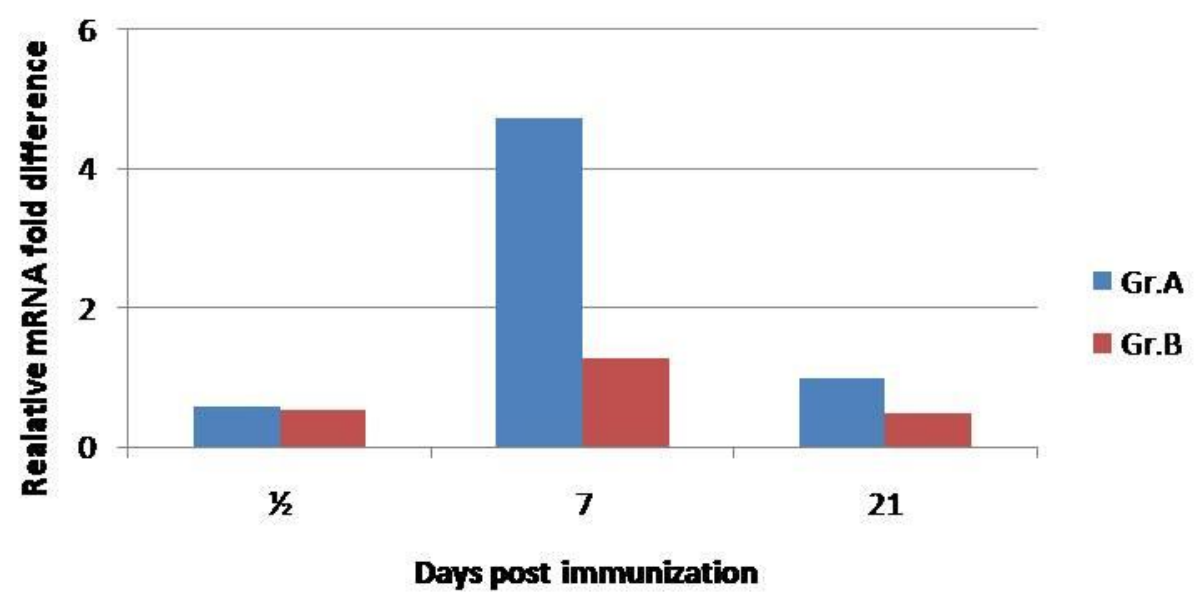


Fig.2 Graphs represent the level of expression of IFN- $\gamma$ and TNF- $\alpha$ in different groups at different time interval in cytokine specific competitive ELISA. (*) indicates $P<0.05$

\section{IFN-Y}

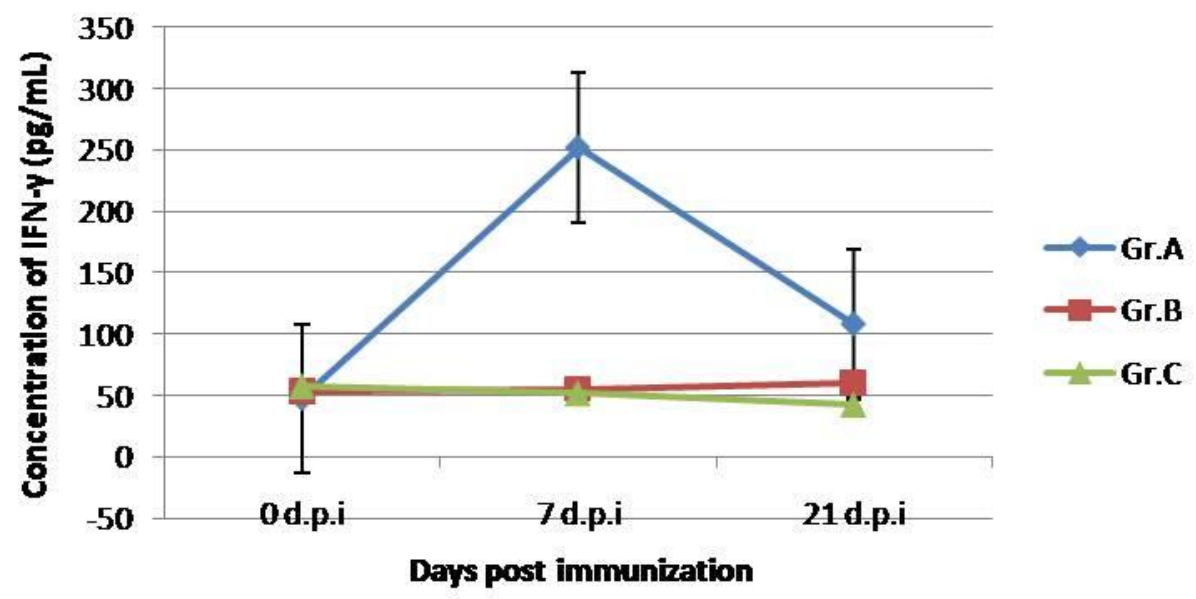

TNF- $\alpha$

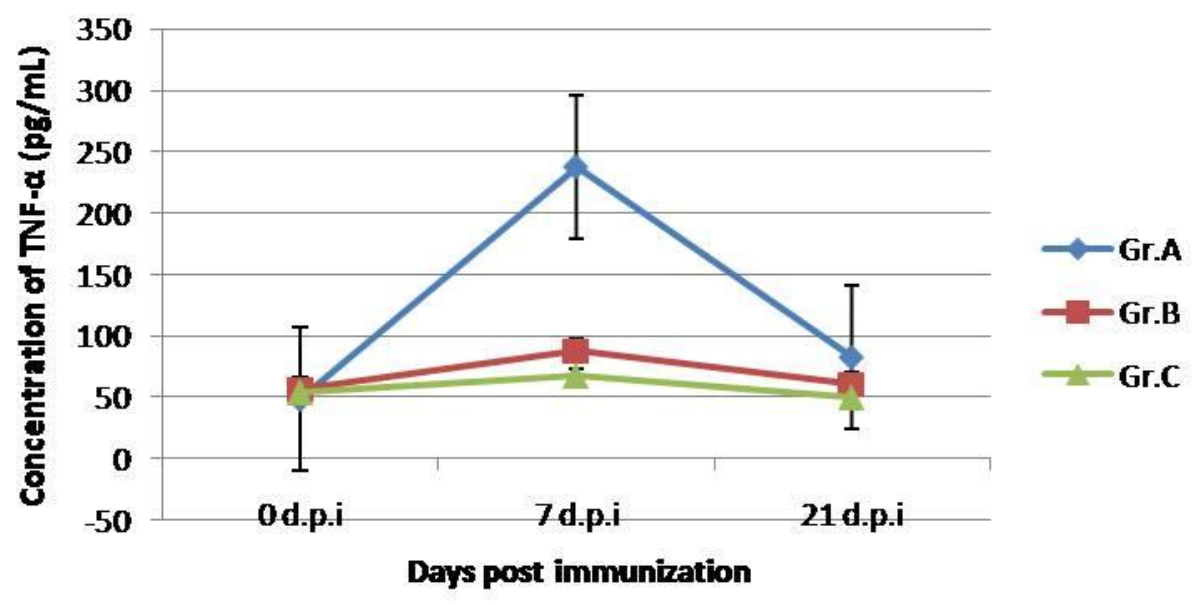


Fig.3 Graphs representing Mean \pm SD percentage of PBMC populations leveled by antibodies against (a) $\mathrm{CD}^{+}$and (b) $\mathrm{CD}^{+} \mathrm{T}$ lymphocytes of different groups of birds at different time intervals. (*) indicates $P<0.05$.

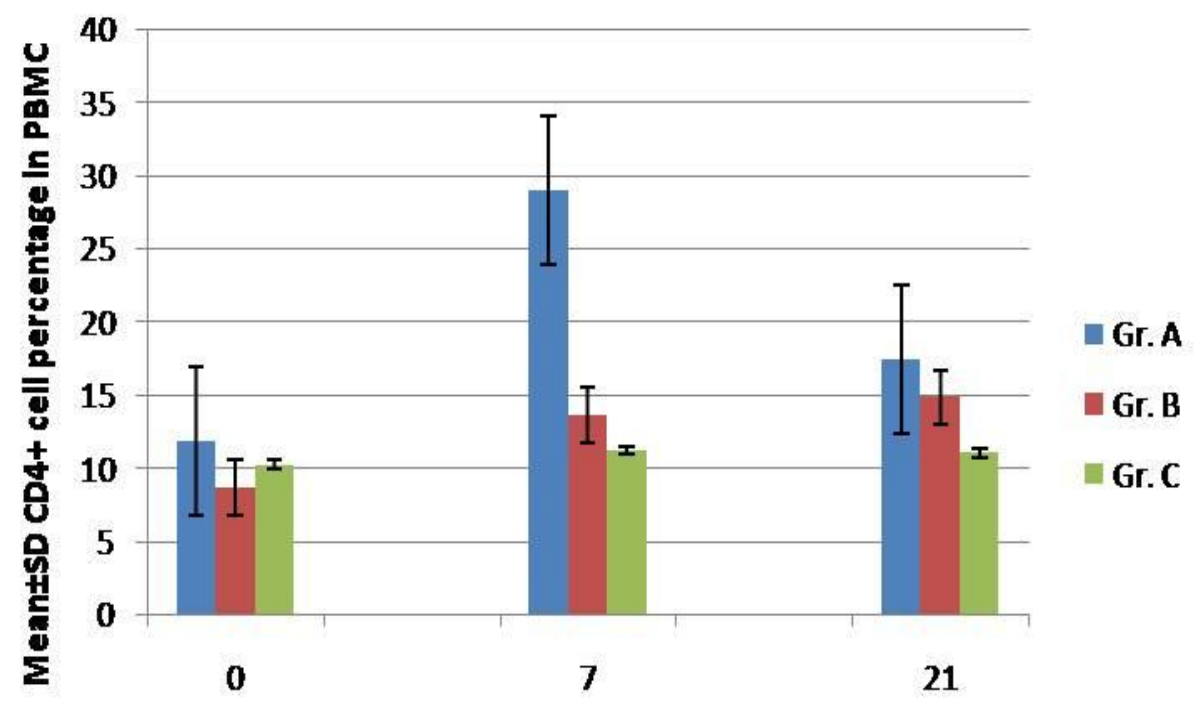

Days post inoculation

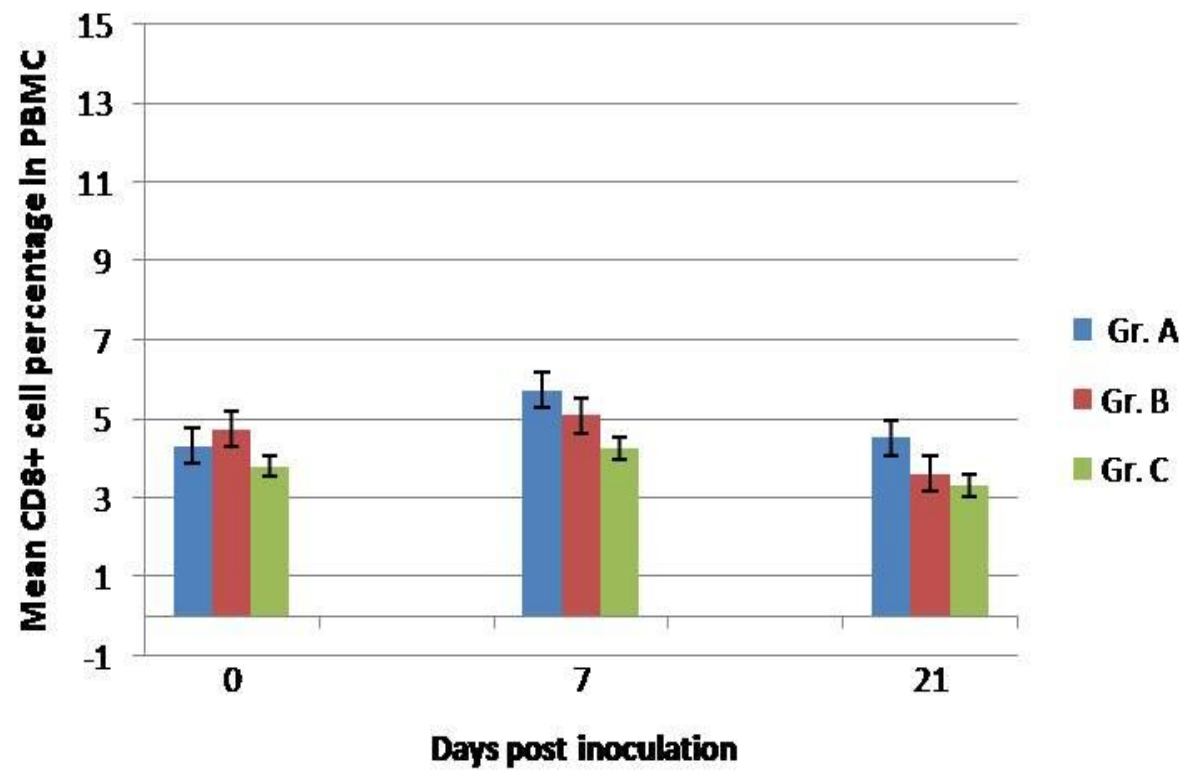


Fig.4 Histogram representing the population of $\mathrm{CD}^{+}$cell population in different groups at different time interval

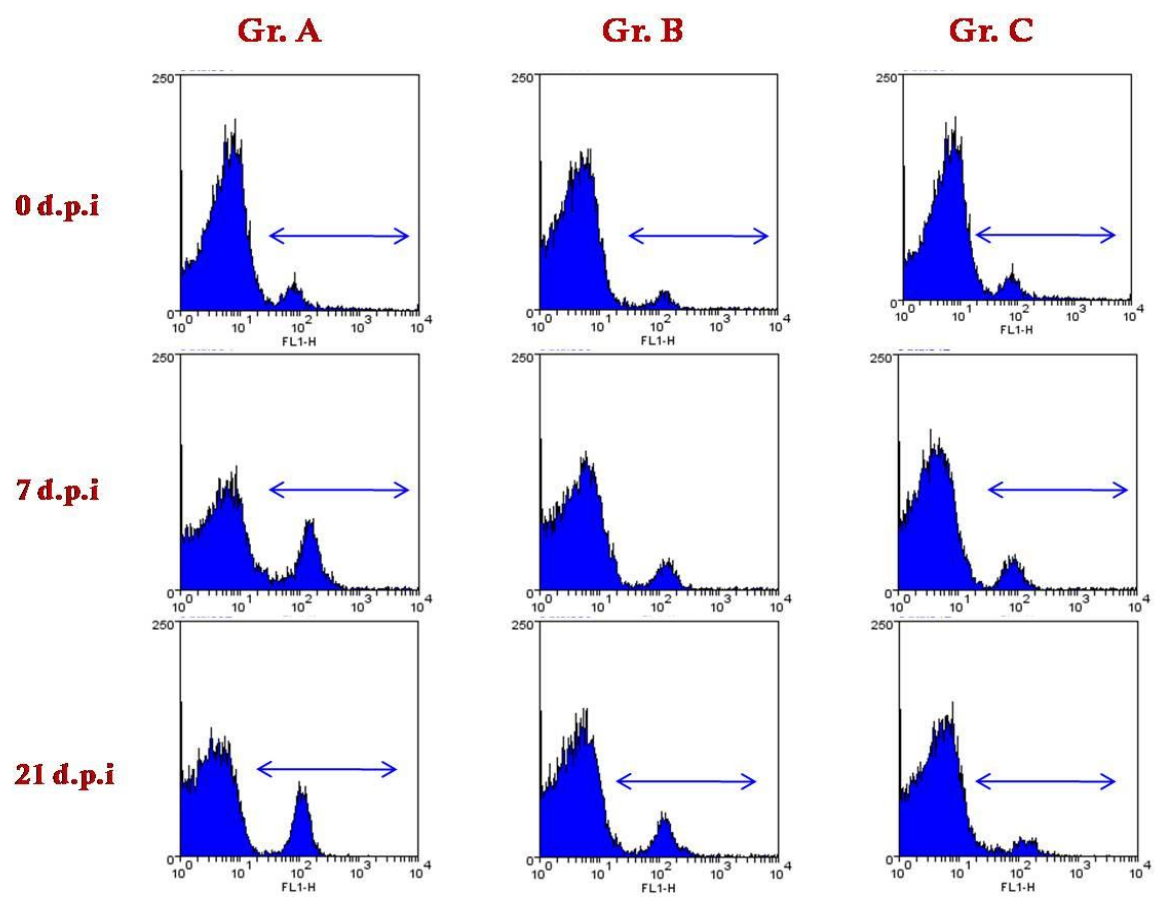

Fig.5 Histogram representing the population of $\mathrm{CD}^{+}$cell population in different groups at different time interval
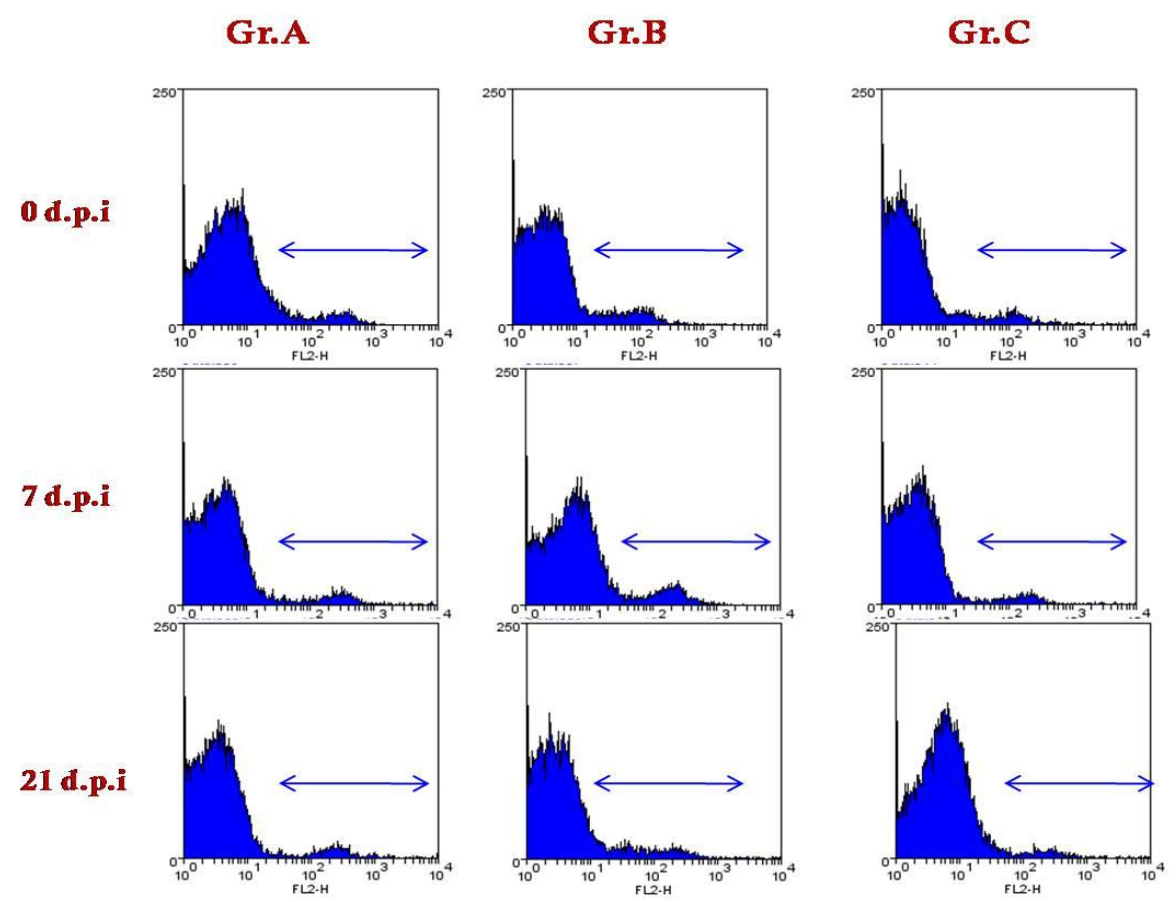
Fig.6 Graphs representing the geometric mean neutralizing (GMT) antibody titre in different groups of birds at different time intervals after immunization with r $\sigma \mathrm{B}$ protein

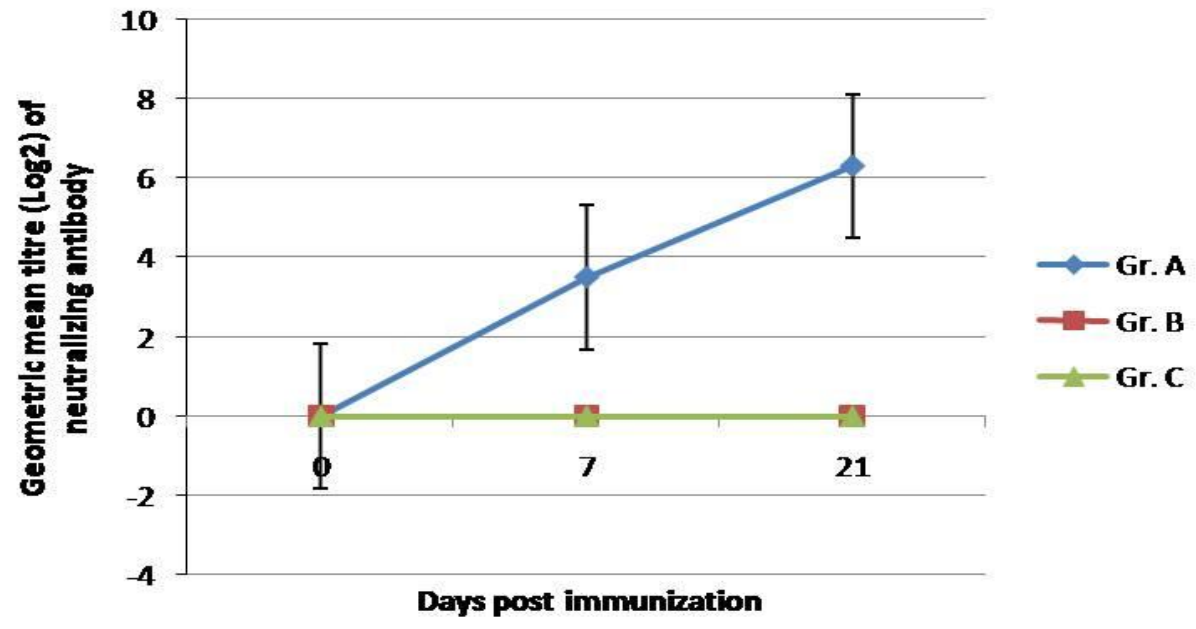

ARV is a widely distributed virus of poultry. It causes considerable economical loss to the poultry industry ( $\mathrm{Lu}$ et al., 2015). It mainly affects the broiler birds, but the layer birds, duck, goose, turkey etc also gets affected by the virus. It causes significant economic losses to the poultry industry. The immunization with potent and efficacious vaccine is the most cost effective and efficient method to control viral disease of man and animal. The goal of immunization is to expose animals to a virus or viral gene product so that they will develop an immune response against the particular pathogen. The vaccines used against ARV are of inactivated and live attenuated in nature. The chicks are vaccinated with live attenuated vaccine and the breeders are vaccinated with inactivated vaccines. The maternal antibody protects the chicks against ARV infection during early days of their life.

Both cell mediated and humoral immune response plays its role in providing protection to the chicken against ARV, though humoral immune response is more important than CMI response (Shapouri et al., 1997). Humoral immunity is mediated by antibodies and it functions to neutralize and eliminate extracellular antigens. Protein antigens activate the $\mathrm{B}$ cell response by a complex process and require participation of several other cells. Protein antigens are first processed in APCs and recognized by helper T lymphocytes, which play an important role in B cell activation and are powerful inducer of heavy chain class switching and affinity maturation. B lymphocytes recognize antigens in lymphoid follicles and encounter Th cells at the edge of follicles. Then $\mathrm{B}$ cell proliferation and differentiation begins at the interface of B-cell rich zones and T-cell rich zones. The antibody secreting cells that develop as a consequence reside in lymphoid organs, and the secreted antibody enters the blood.

The GMT of serum neutralizing antibody in Gr. A birds raised significantly $(P<0.05)$ from 3.5 on 7 d.p.i reaching 6.3 and on 21 d.p.i. There was no detectable neutralizing antibody response in Gr. B and Gr. C birds (Fig. 6). There was significant increase in antibody titers in serum of ducks immunized with recombinant Riemerella anatipestifer outer membrane protein $\mathrm{A}$ and $\mathrm{CpG}$ ODN adjuvant starting on day 7 after initial immunization. The antibody titers peaked on Day 14 and 
remained high for at least 35 days after initial immunization (Chu et al., 2015). Cell mediated immune responses encompasses $\mathrm{T}$ cell response and plays an important role in protection from disease caused by viruses (Zajac and Harrington, 2008). Both $\mathrm{CD}^{+}$and $\mathrm{CD}^{+} \mathrm{T}$ cells are involved in conferring immunity to viral infection through the action of secreted cytokines and cytolytic activity, respectively (Ulmer et al., 1998) (Figs. 4 and 5). Inactivated vaccine preparations and subunit vaccines in general induce $\mathrm{CD}^{+}{ }^{+} \mathrm{T}$ cell responses but not $\mathrm{CD}^{+}$cytotoxic $\mathrm{T}$ lymphocytes (CTL) (Ulmer et al., 1998). CD4+ $\mathrm{T}$ cells differentiate into subsets of effector cells Th1 and Th2 that respond to antigen by producing cytokines that function mainly to activate macrophages and B lymphocytes. One of the important cytokine produced by Th1 cells is IFN- $\gamma$. IFN- $\gamma$ is a potent activator of macrophages, induces expression of class II MHC molecule on APCs, and also stimulates production of antibodies that stimulate the phagocytosis of microbes. Antigen stimulated CD4+ T cells also produce TNF- $\alpha$, causes up regulation of vascular endothelial cell adhesion molecule expression, resulting in recruitment of more $\mathrm{T}$ cells and other leukocytes, including blood neutrophils and monocytes into site of infection (Jersmann et al., 2001). TNF- $\alpha$ is also expressed by activated macrophages, monocytes, neutrophils, activated lymphocytes and NK cells, and plays a pivotal role in regulating the synthesis of other pro- inflammatory cytokines. TNF- $\alpha$ helps in proliferation and differentiation of $\mathrm{T}$ cells, B cells, macrophages, NK cells, and fibroblasts (Channappanavar et al., 2012). TLRs are components of innate immune system and usually expressed by macrophages and DCs and they are important sensors of foreign microbial components (PAMPs). Upon sensing the molecules TLRs initiate downstream signaling event leading to production of cytokine, chemokine and other inflammatory mediators (Li et al., 2010). There was significant increase in IFN- $\gamma$ and TNF- $\alpha$ expression level in Gr. A bird on 7 d.p.i., but in case of control birds there was no change in expression level of these cytokines. These results was supported by both Real Time PCR and cytokine specific competitive ELISA. Similarly here was significant up regulation of IFN- $\gamma$ and TNF- $\alpha$ in-vitro response to recombinant FIP-gsi protein of Ganoderma sinensis in mouse spleen cells ( $\mathrm{Li}$ et al., 2009). In another study it has been shown that there was significant up regulation of mRNA level of IFN- $\gamma$ in chickens experimentally infected with ARV (Shen et al., 2014). The increase in mRNA expression of IFN- $\gamma 7$ dpi may be related to increase in CD4+ Th1 cell subset as evident by flowcytometry and reported by earlier studies (Kano et al., 2009). Sharafeldin et al., (2015) also reported that there was increase in IFN- $\gamma$ followed by experimental ARV infection in chicken 7-14 d.p.i. The increase IFN- $\gamma$ may be due to increase in CD4 T cell 7 d.p.i. In another study it was demonstrated that there was significant increase in IFN- $\gamma$ level 7 day post vaccination with marek disease vaccine (Abdul-Careem et al., 2008). Chu et al., 2015 demonstrated that there is significant up regulation of Th1 cytokine IFN- $\gamma$ followed by immunization with subunit vaccine containing recombinant Riemerella anatipestifer outer membrane protein A and CpG ODN adjuvant.

In Gr. A the mean \pm SD percentage of $\mathrm{CD} 4+$ cells in PBMC raised significantly $(P<0.05)$ from $11.83 \pm 1.56 \%$ in 0 d.p.i reaching peak on 7 d.p.i $28.96 \pm 0.89 \%$ followed by $17.39 \pm$ $0.44 \%$ on 21 d.p.i the CD $4 \%$ was Whereas in $\mathrm{Gr}$. B and $\mathrm{C}$ there was no significant change in CD4+ cell percentage and ranged between $8.68 \pm 1.23 \%-14.82 \pm 0.01 \%$ and $10.2 \pm$ $1.52 \%-12.67 \pm 0.31 \%$ respectively. The CD8+ cells did not show any significant change in proportion throughout the study and ranged between $3.30 \pm 0.87 \% \quad-5.855 \pm$ $0.67 \%$. There was significant increase in 
$\mathrm{CD}^{+} \mathrm{T}$ lymphocytes from day 14 post immunization in ducks immunized with recombinant Riemerella anatipestifer outer membrane protein A and $\mathrm{CpG}$ ODN adjuvant (Chu et al., 2015).

\section{References}

Abdul-Careem, M.F., Hunter, D.B., Lambourne, M.D., Read, L.R., Parvizi, P., Sharif, S. 2008. Expression of cytokine genes following pre- and post-hatch immunization of chickens with herpesvirus of turkeys. Vaccine, 26: 2369-2377.

doi:10.1016/j.vaccine.2008.02.069

Akira, S. 2003. Toll-like Receptor Signaling. $J$. Biol. Chem., 278: 38105-38108. doi:10.1074/jbc.R300028200

Arnauld, C., Jestin, V., Blanchard, P., Jestin, A., Cherbonnel, M., Le Gall-Recul, G. 1999. Molecular characterization and expression of the S3 gene of muscovy duck reovirus strain 89026. J. Gen. Virol., 80: 195-203. doi:10.1099/0022-1317-801-195

Bodelón, G., Labrada, L., Martínez-Costas, J., Benavente, J. 2001. The Avian Reovirus Genome Segment S1 Is a Functionally Tricistronic Gene That Expresses One Structural and Two Nonstructural Proteins in Infected Cells. Virol., 290: 181-191. doi:10.1006/viro.2001.1159

Chang, J. 1998. Adjuvant activity of incomplete Freund's adjuvant. Adv. Drug Deliv. Rev., 32: $\quad 173-186 . \quad$ doi:10.1016/S0169409X(98)00009-X

Channappanavar, R., Twardy, B.S., Suvas, S. 2012. Blocking of PDL-1 Interaction Enhances Primary and Secondary CD8 T Cell Response to Herpes Simplex Virus-1 Infection. PLoS One, 7: e39757. doi:10.1371/journal.pone.0039757

Chu, C.Y., Liu, C.H., Liou, J.J., Lee, J.W., Cheng, L.T. 2015. Development of a subunit vaccine containing recombinant Riemerella anatipestifer outer membrane protein $\mathrm{A}$ and $\mathrm{CpG}$ ODN adjuvant.
Vaccine, 33: 92-99. doi:10.1016/j.vaccine.2014.11.010

Fahey, J.E., Crawley, J.F. 1954. Studies On Chronic Respiratory Disease Of Chickens II. Isolation of Virus. Can. J. Comp. Med. Vet. Sci., 18: 13-21.

Giambrone, J.J. 1980. Microculture Neutralization Test for Serodiagnosis of Three Avian Viral Infections. Avian Dis., 24: 284. doi:10.2307/1589788

Jersmann, H.P.A., Hii, C.S.T., Ferrante, J.V., Ferrante, A. 2001. Bacterial Lipopolysaccharide and Tumor Necrosis Factor Alpha Synergistically Increase Expression of Human Endothelial Adhesion Molecules through Activation of NF- B and p38 Mitogen-Activated Protein Kinase Signaling Pathways. Infect. Immun., 69: 1273-1279. doi:10.1128/IAI.69.3.1273-1279.2001

Kano, R., Konnai, S., Onuma, M., Ohashi, K. 2009. Cytokine profiles in chickens infected with virulent and avirulent Marek's disease viruses: Interferongamma is a key factor in the protection of Marek's disease by vaccination: MD vaccination induces IFN- $\gamma$ expression. Microbiol. Immunol., 53: 224-232. doi:10.1111/j.1348-0421.2009.00109.x

Li, X., Jiang, S., Tapping, R.I. 2010. Toll-like receptor signaling in cell proliferation and survival. Cytokine, 49: 1-9. doi:10.1016/j.cyto.2009.08.010

Nang, N., Lee, J., Song, B., Kang, Y., Kim, H., Seo, S. 2011. Induction of inflammatory cytokines and toll-like receptors in chickens infected with avian H9N2 influenza virus. Vet. Res., 42: 64. doi:10.1186/1297-9716-42-64

Ni, Y., Ramig, R.F. 1993. Characterization of Avian Reovirus-Induced Cell Fusion: The Role of Viral Structural Proteins. Virol., 194: 705-714. doi:10.1006/viro.1993.1311

Nkando, I., Perez-Casal, J., Mwirigi, M., Prysliak, T., Townsend, H., Berberov, E., Kuria, J., Mugambi, J., Soi, R., Liljander, A., Jores, J., Gerdts, V., Potter, A., Naessens, J., Wesonga, H. 2016. Recombinant Mycoplasma mycoides 
proteins elicit protective immune responses against contagious bovine pleuropneumonia. Vet. Immunol. Immunopathol., $\quad 171$ : 103-114. doi:10.1016/j.vetimm.2016.02.010

Pfaffl, M.W. 2001. A new mathematical model for relative quantification in real-time RT-PCR. Nucleic Acids Res., 29: 45e-45. doi:10.1093/nar/29.9.e45

Shapouri, M.R.S., Arella, M., Silim, A. 1997. Immunogenicity of $E$. coli -expressed $\sigma 3$ protein of avian reovirus in chickens. Avian Pathol., 26: 419-425. doi:10.1080/03079459708419223

Sharafeldin, T.A., Mor, S.K., Sobhy, N.M., Xing, Z., Reed, K.M., Goyal, S.M., Porter, R.E. 2015. A Newly Emergent Turkey Arthritis Reovirus Shows Dominant Enteric Tropism and Induces Significantly Elevated Innate Antiviral and T Helper-1 Cytokine Responses. Plos One, 10: e0144085. doi:10.1371/journal. pone. 0144085

Shen, P.C., Yang, J.L., Su, B.S., Lee, L.H. 2014. Cytokine mRNA expression in chicken experimentally infected with different avian reovirus strains. Taiwan Vet. $\quad J ., \quad 40:$ 29-36. doi:10.1142/S1682648514500048

Spandidos, D., Graham, A., 1976. Physical and chemical characterization of an avian reovirus. J. Virol., 19: 968-976.

Takase, K., Fujikawa, H., Yamada, S., 1996. Correlation between neutralizing antibody titre and protection from tenosynovitis in avian reovirus infections. Avian Pathol., 25: 807-815. doi:10.1080/03079459608419183

Ulmer, J.B., Tong-Ming, F., Deck, R.R., Friedman, A., Guan, L.M., DeWitt, C., $\mathrm{Xu}, \quad$ L., Wang, S., Margaret, A.L., donnelly, J.J., Caulfield, M.J. 1998. Protective CD41 and CD81 T Cells against Influenza Virus Induced by Vaccination with Nucleoprotein DNA. $J$. Virol., 72: 5648-53.

Varela, R., Martínez-Costas, J., Mallo, M., Benavente, J. 1996. Intracellular posttranslational modifications of S1133 avian reovirus proteins. J. Virol., 70: 2974-2981.

Wickramasinghe, R., Meanger, J., Enriquez, C.E., Wilcox, G.E. 1993. Avian reovirus proteins associated with neutralization of virus infectivity. Virol., 194: 688-696. doi:10.1006/viro.1993.1309

Zajac, A.J., Harrington, L.E. 2008. Immune Response to Viruses: Cell-Mediated Immunity, in: Encyclo. Virol., 70-77.

Zhang, Y., Guo, D., Liu, M., Geng, H., Hu, Q., Liu, Y., Liu, N. 2007. Characterization of the $\sigma \mathrm{B}$-encoding genes of muscovy duck reovirus: $\sigma \mathrm{C}-\sigma \mathrm{B}-\mathrm{ELISA}$ for antibodies against duck reovirus in ducks. Vet. Microbiol., 121: 231-241. doi:10.1016/j.vetmic.2006.12.008.

\section{How to cite this article:}

Majumder, S., T.K.S. Chauhan, K. Dhama, S. Nandi, P.P. Goswami and Deepak Kumar. 2017. Evaluation of immune response to $r \mathrm{~B}$ protein of Avian reovirus (ARV) in chicken. Int.J.Curr.Microbiol.App.Sci. 6(4): 1496-1507. doi: https://doi.org/10.20546/ijcmas.2017.604.183 